\title{
Elucidating the Mechanism of Oxygen Reduction for Lithium-Air Battery Applications
}

\author{
Cormac O. Laoire, Sanjeev Mukerjee, and K. M. Abraham* \\ Department of Chemistry and Chemical Biology, Northeastern University, 360 Huntington Avenue, \\ Boston, Massachusetts 02115
}

\author{
Edward J. Plichta and Mary A. Hendrickson \\ U.S. Army CERDEC, Army Power Division, Ft. Monmouth, New Jersey 07703
}

Received: August 21, 2009; Revised Manuscript Received: September 28, 2009

\begin{abstract}
Unlocking the true energy capabilities of the lithium metal negative electrode in a lithium battery has until now been limited by the low capacity intercalation and conversion reactions at the positive electrodes. Abraham et al. (Abraham, K. M.; Jiang, Z. J. Electrochem. Soc. 1996, 143, 1-5) overcame this limitation by removing these electrodes and allowing lithium to react directly with oxygen in the atmosphere, forming the Li-air battery. The $\mathrm{Li} / \mathrm{O}_{2}$ battery redox couple has a theoretical specific energy of $5200 \mathrm{~W} \mathrm{~h} / \mathrm{kg}$ and represents the ultimate, environmentally friendly electrochemical power source. In this work, we report for the first time the intimate role of electrolyte, in particular the role of ion conducting salts, in determining the reversibility and kinetics of oxygen reduction in nonaqueous electrolytes designed for such applications. Such fundamental understanding of this high energy density battery is crucial to harnessing its full energy potential. The kinetics and mechanisms of $\mathrm{O}_{2}$ reduction in solutions of hexafluorophosphate of the general formula $\mathrm{A}^{+} \mathrm{PF}_{6}{ }^{-}$, where $\mathrm{A}=$ tetrabutylammonium (TBA), $\mathrm{K}$, $\mathrm{Na}$, and $\mathrm{Li}$, in acetonitrile are reported on glassy carbon electrodes using cyclic voltammetry $(\mathrm{CV})$ and rotating disk electrode $(\mathrm{RDE})$ techniques. The results show that the cations in the electrolyte strongly influence the reduction mechanism of $\mathrm{O}_{2}$. Larger cations represented by TBA salts displayed reversible $\mathrm{O}_{2} / \mathrm{O}_{2}{ }^{-}$redox couple, in contrast to those containing the smaller $\mathrm{Li}$ (and other alkali metal) cations, where an irreversible one-electron reduction of $\mathrm{O}_{2}$ to $\mathrm{LiO}_{2}$, and other alkali metal superoxides, is shown to occur as the first process. It was also found the $\mathrm{LiO}_{2}$ formed initially decomposes to $\mathrm{Li}_{2} \mathrm{O}_{2}$. Electrochemical data support the view that alkali metal oxides formed via electrochemical and chemical reactions passivate the electrode surface, making the processes irreversible. The $\mathrm{O}_{2}$ reduction mechanisms in the presence of the different cations have been supplemented by kinetic parameters determined from detailed analyses of the CV and RDE data. The Lewis acid characteristics of the cation appear to be crucial in determining the reversibility of the system. The results of this study are expected to contribute to the rapid development of the Li-air battery.
\end{abstract}

\section{Introduction}

The lithium-air battery is one of the most energy dense, and environmentally friendly, electrochemical power sources. Fully developed and optimally packaged Li-air batteries could exceed specific energies of $2000 \mathrm{~W} \mathrm{~h} / \mathrm{kg}$, versus a theoretical value of $5200 \mathrm{~W} \mathrm{~h} / \mathrm{kg}$, which is more than twice as much as any battery, primary or secondary, presently known. The Li-air battery is composed of a Li metal anode and an air cathode in which the cathode active material, oxygen, is accessed from the environment. The first nonaqueous, rechargeable, Li-air battery ${ }^{1}$ used $\mathrm{Li}^{+}$-conducting gel polymer electrolytes based on polyacrylonitrile (PAN) or polyvinylidene fluoride (PVDF). In that battery, $\mathrm{Li}_{2} \mathrm{O}_{2}$ was identified as a product of the discharge reaction which in presence of catalysts could be oxidized (recharged), albeit at high overvoltages, to oxygen and lithium metal. Later studies of Li-air batteries utilized organic carbonate- and ether-based electrolytes of the types used in Li metal and Li-ion batteries. ${ }^{2}$ In a recent study, Bruce and co-workers ${ }^{3}$ demonstrated the possibility of using $\mathrm{Li}_{2} \mathrm{O}_{2}$ as a positive electrode material in a Li-air battery which was activated by initially charging (oxidizing) the peroxide to oxygen and lithium metal. The electro-

* Author to whom technical correspondence should be addressed. E-mail: kmabraham@comcast.net. chemical reduction of oxygen to superoxide and other oxides can be taken advantage of practically, as they can behave as Lewis bases, nucleophiles, as a well as both oxidizing and reducing agents. These traits make the reduction of oxygen desirable for energy production and storage. Previous electrochemical studies of the oxygen reduction reaction (ORR) in organic solvents ${ }^{4-7}$ demonstrated that it is possible to reduce molecular oxygen to superoxide $\left(\mathrm{O}_{2}^{-}\right)$in a nonaqueous environment. An identified distinction between the use of nonaqueous and aqueous electrolytes is that in aqueous electrolytes the preferred reduction product is water or hydrogen peroxide corresponding to a four- or two-electron reduction of $\mathrm{O}_{2}$, respectively, as opposed to the formation of superoxide in organic electrolytes. Almost all of the prior research in organic electrolytes utilized quaternary-ammonium-cation $\left(\mathrm{NR}_{4}{ }^{+}\right.$where, $R=$ ethyl, butyl, etc.)-based salts as supporting electrolytes for ion conduction. We are interested in understanding the electrochemistry of oxygen in organic electrolytes in the presence of alkali metal cations such as $\mathrm{Li}^{+}, \mathrm{Na}^{+}$, and $\mathrm{K}^{+}$in an effort to apply oxygen chemistry toward nonaqueous metal-air batteries, particularly $\mathrm{Li}$ and $\mathrm{Na}$ batteries. These results together with the early investigations of oxygen electrochemistry in nonaqueous electrolytes suggest that more than one product is possible in the electrochemical reduction of nonaqueous Li-air batteries and 
that a good understanding of the mechanism of oxygen reduction in organic electrolyte is lacking. An in-depth study of the electrochemical redox behavior of $\mathrm{O}_{2}$, including the kinetics and transport properties of the reduction and oxidation products in the electrolyte, is important in further developing the Li-air battery. To this end, we have initiated studies of the redox reactions of oxygen in nonaqueous electrolytes with the objective of elucidating the roles of ion conducting salts and organic solvents on the mechanisms of the corresponding reactions. In this paper, we present a full account of our work in acetonitrile. This solvent is not practically useful in a Li-air battery because it reacts with Li metal. Despite this, we chose it for this initial study because of previous electrochemical studies of oxygen in this solvent and because of some initial surprising results we obtained when a Li salt was used as the conducting salt. Most of the early electrochemistry of molecular oxygen in organic solvents such as dimethyl sulfoxide (DMSO), dimethylformamide (DMF), and acetonitrile ${ }^{4-6}$ utilized tetraalkylammonium perchlorate $\left(\mathrm{NR}_{4}{ }^{+} \mathrm{ClO}_{4}\right)$ as the ion conducting salts, leading to similar overall results. We show here that there are significant differences in the reduction mechanism and products when alkali metal salts are used. (Our results in other practically more relevant organic electrolytes for the Li-air battery will be published in the future). Using cyclic voltammetry (CV) and rotating disk electrode (RDE) voltammetry, we first studied $\mathrm{O}_{2}$ reduction in acetonitrile electrolyte solutions containing both $\mathrm{TBAClO}_{4}$ and $\mathrm{TBAPF}_{6}$ to assess the influence of anion on oxygen reduction. We then studied oxygen redox reactions in hexafluorophosphate-based electrolytes of the formula $\mathrm{A}^{+} \mathrm{PF}_{6}{ }^{-}$ where $\mathrm{A}=\mathrm{TBA}, \mathrm{K}, \mathrm{Na}, \mathrm{Li}$. We have discovered that the electrochemistry of oxygen is strongly influenced by the nature of the cation and very little by the anion in the conducting salt. Also, our RDE studies reported here represent the first application of this technique to elucidate the mechanism of oxygen reduction in nonaqueous electrolytes, and the results for the first time provide detailed information on the influence of supporting electrolytes on the kinetics and mechanisms of oxygen reduction in nonaqueous electrolytes.

\section{Experimental Section}

Chemical Reagents. All reagents were electrochemical grade unless stated otherwise. Battery grade solvents and lithium hexafluorophosphate $\left(\mathrm{LiPF}_{6}\right)$ (battery grade, $>99.9 \%, \mathrm{H}_{2} \mathrm{O}<20$ ppm) were obtained from Ferro Corporation, Cleveland, $\mathrm{OH}$. Tetrabutylammoniumhexaflourophosphate $\left(\mathrm{TBAPF}_{6}\right)$, anhydrous acetonitrile $(\mathrm{MeCN})$, tetrabutylammonium perchlorate (TBA$\left.\mathrm{ClO}_{4}\right)$, potassium hexafluorophosphate $\left(\mathrm{KPF}_{6}\right)$, and sodium hexafluorophosphate $\left(\mathrm{NaPF}_{6}\right)$ were purchased from SigmaAldrich, Allentown, PA.

Instrumentation. The electrochemical experiments were performed with an Autolab (Ecochemie Inc., model-PGSTAT 30) potentiostat equipped with a bipotentiostat interface in an airtight electrochemical cell. The electrochemical cell designed and built in-house consisted of a traditional three-electrode system utilizing $\mathrm{Ag} / \mathrm{AgCl}$ as the reference electrode and platinum wire as the counter electrode. This reference electrode was used instead of the $\mathrm{Li}$ foil electrode typically used in $\mathrm{Li}^{+}$ conducting electrolytes because of its instability as a reference electrode in this electrolyte. The $\mathrm{Ag} / \mathrm{AgCl}$ gives a voltage of $2.93 \mathrm{~V}$ versus $\mathrm{Li} / \mathrm{Li}^{+}$, as measured using a $\mathrm{Li}$ foil reference electrode in a $\mathrm{LiPF}_{6}$ solution in organic carbonates. The cell also had inlet and outlet valves for oxygen or argon purging. The cell was entirely airtight with exception of the gas outlets, which were kept under pressure with the working gas. The
TABLE 1: Conductivity and Viscosity of the Electrolyte Solutions in Acetonitrile

\begin{tabular}{lcc}
\hline \multicolumn{1}{c}{ electrolyte } & $\begin{array}{c}\text { kinematic viscosity, } \\
v\left(\mathrm{~cm}^{2} \mathrm{~s}^{-1}\right) \pm 0.003 \\
\mathrm{~cm}^{2} \mathrm{~s}^{-1}\end{array}$ & $\begin{array}{c}\text { conductivity, } \\
\sigma\left(\mathrm{m} \mathrm{cm}^{-1}\right)\end{array}$ \\
\hline acetonitrile & 0.00440 & \\
$0.1 \mathrm{M} \mathrm{TBAPF} /$ acetonitrile & 0.00442 & 14.39 \\
$0.1 \mathrm{M} \mathrm{LiPF} /$ acetonitrile & 0.00461 & 10.85 \\
$0.1 \mathrm{M} \mathrm{NaPF} /$ acetonitrile & 0.00456 & 12.50 \\
$0.1 \mathrm{M} \mathrm{KPF} /$ acetonitrile & 0.00451 & 14.02
\end{tabular}

glassy carbon (3 mm diameter) working electrode employed for the cyclic voltammetry experiments was polished with 0.5 and $0.05 \mathrm{~mm}$ alumina paste prior to the experiments. For RDE experiments, the glassy carbon electrode was rotated with an Autolab RDE rotor. All of the cyclic voltammetry experiments were initially performed in an Ar-atmosphere glovebox where $\mathrm{H}_{2} \mathrm{O}$ and $\mathrm{O}_{2}$ concentrations were kept below $5 \mathrm{ppm}$ and temperature was held at $22 \pm 2{ }^{\circ} \mathrm{C}$. For RDE experiments, the cell was brought outside of the glovebox and placed in a glovebag purged with argon. The electrolyte solutions were first purged with argon, and the electrode was cycled continuously until a reproducible cyclic voltammetric profile was obtained. The solutions were then purged with $\mathrm{O}_{2}$ for ORR measurements. All solutions were prepared in the glovebox. Conductivity measurements of all samples were carried out using a fourprobe Thermo Orion conductivity cell from Thermo Fisher Scientific Inc., Waltham, MA. Viscosity was measured using an Ubbelohde viscometer purchased from Technical Glass Products Inc., NJ.

\section{Results and Discussion}

The roles of the TBA and alkali metal salts on the reduction properties of molecular oxygen $\left(\mathrm{O}_{2}\right)$ in acetonitrile were studied using cyclic $(\mathrm{CV})$ and rotating disk electrode (RDE) voltammetry. Cyclic voltammetry is a useful technique for discerning kinetics and mechanisms of electrochemical reactions. It is an electrochemical potential sweep reversal method wherein a certain potential range is swept at a known scan rate (measured in volt per second) in both the negative and positive directions and the change in current is recorded. By applying appropriate equations, the $\mathrm{CV}$ data can tell whether the reaction is nernstian (reversible), quasi-reversible, or irreversible. The RDE technique can be used in a complementary fashion to discern the mechanistic details of the electrochemical processes. The same disk electrode can be used to run both $\mathrm{CV}$ and RDE scans. The rotating disk, hydrodynamic, technique utilizes convection as the mode of mass transport as opposed to $\mathrm{CV}$, which is governed by diffusion. Convection is a more efficient means of mass transport with the result that the analytical data are more reproducible and precise. In Table 1 , the conductivities and viscosities of the electrolyte solutions used in this study are presented. Some of these physical properties are used in calculating kinetic parameters discussed below.

3.1. Oxygen Reduction in Tetrabutylammonium-Hexafluorophosphate ( $\mathrm{TBA}^{+} \mathrm{PF}^{-}{ }_{6}$ )-Based Electrolytes. The full-range cyclic voltammograms (CVs) scanned from -3 to $1 \mathrm{~V}$ for the reduction of oxygen in $0.1 \mathrm{M} \mathrm{TBAPF}_{6}$ and $\mathrm{TBAClO}_{4} / \mathrm{MeCN}$ are presented in Figure 1A. CVs were first run under an inert atmosphere of argon to provide a background voltammogram. As shown, no appreciable current was observed under argon over the full potential range of which oxygen redox reactions were investigated, confirming that the electrolyte contained no other electroactive species. The similarity of the voltammograms 


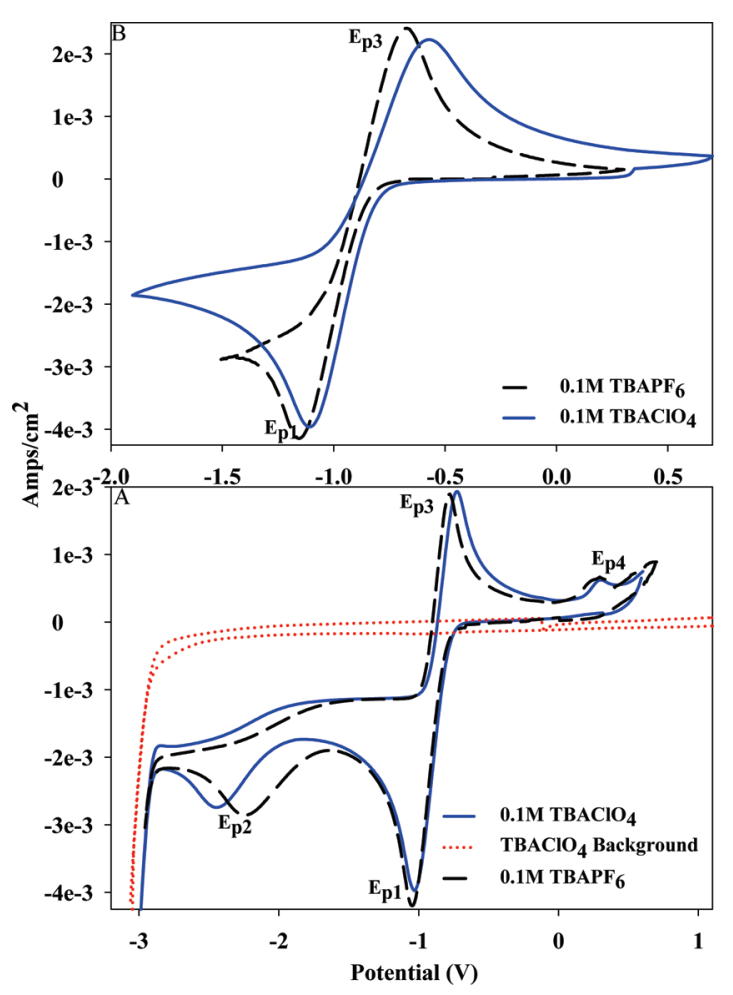

Figure 1. (A) $i R$ corrected voltammograms for the reduction of oxygen in $0.1 \mathrm{M} \mathrm{TBAPF}_{6}$ (black), $0.1 \mathrm{M} \mathrm{TBAClO}_{4}$ (blue), and the argon background (dotted) in $\mathrm{MeCN}$. (B) $\mathrm{CVs}$ in the -2 to $+0.5 \mathrm{~V}$ range. All scans used a glassy carbon working electrode. Scan rate $=100$ $\mathrm{mV} \mathrm{s}^{-1}$.

TABLE 2: Electrochemical Charge Area under the Peaks ${ }^{a}$

\begin{tabular}{cccccc}
\hline charge area $\left(\times 10^{-3} \mathrm{C}\right)$ & $E_{\mathrm{p} 1}$ & $E_{\mathrm{p} 2}$ & $E_{\mathrm{p} 3}$ & $E_{\mathrm{p} 1}-\mathrm{IR}$ & $E_{\mathrm{p} 2}-\mathrm{IR}$ \\
\hline $\mathrm{ClO}_{4}^{-}$ & 4.98 & 1.45 & 3.47 & 4.91 & 4.30 \\
$\mathrm{PF}_{6}^{-}$ & 4.72 & 1.31 & 3.30 & 3.7 & 3.3
\end{tabular}

${ }^{a}$ Scan rate $=100 \mathrm{mV} \mathrm{s}^{-1}$. Error $\pm 0.002 \mathrm{C}$.

is quite evident; the first reduction peak $\left(E_{\mathrm{p} 1}\right)$ at ca. $-0.9 \mathrm{~V}$ is present in both CVs with little difference in peak position. Polarizing the electrode to further negative potentials, a second reduction peak $\left(E_{\mathrm{p} 2}\right)$ emerges at ca. $-2.2 \mathrm{~V}$, also present in both electrolytes. The oxidation peak $\left(E_{\mathrm{p} 3}\right)$ peak is very similar in shape and size to that of $E_{\mathrm{p} 1}$ and only slightly separated in the $\mathrm{ClO}_{4}{ }^{-}$case. This can only be attributed to the subsequent oxidation of $E_{\mathrm{p} 1}$ reduction products. $E_{\mathrm{p} 4}$ is separated from $E_{\mathrm{p} 2}$ by almost $2 \mathrm{~V}$, highlighting an irreversible reaction. In fact, $E_{\mathrm{p} 2}$ 's reduction products are oxidized only at these high overpotentials. By integrating the area under each peakb we find the charge area. The charge area under $E_{\mathrm{p} 1}$ and $E_{\mathrm{p} 3}$ peaks is similar. However, expanding the electrochemical window to encompass $E_{\mathrm{p} 2}$, we see a distinct loss in charge area under the anodic peak $\left(E_{\mathrm{p} 3}\right)$. Comparing this loss of charge to the area under $E_{\mathrm{p} 2}$, we find this area is proportional to that of the loss (Table 2), thus implying a portion of the first reduction product formed on the electrode undergoes a secondary irreversible reduction. The peak $E_{\mathrm{p} 4}$ appears if the second reduction peak $E_{\mathrm{p} 2}$ is formed, and hence, we associate it with the oxidation of the material generated at the electrode during this process. This can be clearly discerned from CVs in Figure 1B, where the scan region is restricted to avoid $E_{\mathrm{p} 2}$. Generally speaking, these voltammograms are identical except for peak positions, which may be attributed to ohmic losses. This weak but noticeable oxygen reduction dependence on the counterion is evident by these shifts. ORR in perchlorate solution is slightly positive by
$100 \mathrm{mV}$, indicating that oxygen reduction in the presence of hexafluorophosphate is to some extent slightly polarized. This may be due in part to the less coordinating nature of the $\mathrm{PF}_{6}{ }^{-}$, allowing the larger tetrabutylammonium ion to interact with dissolved oxygen. Generally, the electrolyte/electrode interface is affected by the nature of the counterion. A summary of voltammetric results is provided in Table 3. These results indicate that the solvent/salt interactions are well coordinated in the case of $\mathrm{TBAClO}_{4}$, leading to a structured double layer region, which is coupled to the ion diffusion coefficients. We found the charge area ratio $\left(Q_{\mathrm{a}} / Q_{\mathrm{c}}\right)$ under the peaks to be over $89 \pm 0.02 \%$ for the CVs portrayed in Figure 1B. The peak potential separations $\Delta E_{\mathrm{p}}$ between the anodic and cathodic peak potentials for $\mathrm{ClO}_{4}{ }^{-}$and $\mathrm{PF}_{6}{ }^{-}$are presented in Table 3. These values are close to the theoretical value of $59 \mathrm{mV}$ for a oneelectron reaction. For a reversible process, the peak width is given by the following relationship.

$$
E_{\mathrm{p} / 2}-E_{\mathrm{p}}=2.2\left(\frac{R T}{n F}\right)
$$

where $E_{\mathrm{p} / 2}$ is the half-peak potential at the half-value of the peak current, $i_{\mathrm{p}}$ is the peak potential, $F$ is the Faraday constant, and $n$ is the number of electrons in the reaction. Analysis of the CVs over the whole sweep ranges gave $n$ values close to unity (see Table 3), indicating that the number of electrons transferred in the reaction is 1 . Possible reasons $\Delta E_{\mathrm{p}}$ is slightly larger than the theoretical value are sluggish kinetics due to ohmic $(i R)$ contributions $\left(E_{\text {true }}=E_{\text {actual }}-i R\right)$ at high scan rates. The magnitude of the current $(I)$ in cyclic voltammetry is a function of temperature $T$, concentration $C$, electrode area $A$, the number of electrons transferred $n$, the diffusion coefficient $D$, and the speed at which the potential is scanned $V$, all related by the Randles-Sevcik equation (eq 2).

$$
I_{\mathrm{pa}}=\left(2.69 \times 10^{5}\right) n^{3 / 2} A D^{1 / 2} V^{1 / 2} C
$$

Figure 2A displays the cyclic voltammograms for the reduction of oxygen-saturated $\mathrm{TBAPF}_{6} / \mathrm{MeCN}$ at different sweep rates. The reduction is reversible at all sweep rates, and there is only a slight shift in the peak position. The Randles-Sevcik plots presented in Figure 2B are linear and pass through the origin as per theory, indicating a fast, diffusion controlled electrochemical process. The theoretical plot of $n=1$ in Figure 2B parallels the one-electron experimental plot, implying that $n=1$ and that the first reduction involves the formation of superoxide $\left(\mathrm{O}_{2}^{-}\right)$. The presence of superoxide in solution was confirmed qualitatively by adding a nitrotetrazolium blue chloride tablet, which produced the characteristic purple color. Figure 3A shows the typical steady-state voltammograms for $\mathrm{O}_{2}$ reduction on a RDE in oxygen-saturated $0.1 \mathrm{M} \mathrm{TBAPF}_{6}$ solution at various rotation rates. This figure demonstrates that the current generated by this hydrodynamic method is much larger than that generated in the CV under diffusion control. The much larger current obtained using RDE reflects the efficiency of this method. We can easily determine the limiting current, $i_{\text {lim }}$, from these voltammograms. Also notice in the figure that there is significant increase in cathodic current (i.e., $\mathrm{O}_{2}$ to $\mathrm{O}_{2}{ }^{-}$) while the amount of anodic current (i.e., $\mathrm{O}_{2}{ }^{-}$to $\mathrm{O}_{2}$ ) is negligible, essentially making the voltammogram cathodic. This is due to the vast difference in the concentrations of $\mathrm{O}_{2}$ and the $\mathrm{O}_{2}{ }^{-}$ions. The bulk solution contains $\mathrm{O}_{2}$, which is constantly supplied to the rotating electrode, while the superoxide ion's 
TABLE 3: Voltammetric Properties of $\mathrm{O}_{2} / \mathrm{O}_{2}^{-}$Redox Couple in $0.1 \mathrm{M}$ TBAPF 6 and $\mathrm{TBAClO}_{4} / \mathrm{MeCN}$

\begin{tabular}{|c|c|c|c|c|c|}
\hline $\begin{array}{l}\text { scan rate, } V \\
\left(\mathrm{mV} \mathrm{s}^{-1}\right)\end{array}$ & $\begin{array}{c}E_{\mathrm{pa}} \pm \\
0.002 \mathrm{~V}, \mathrm{ClO}_{4}^{-} \\
\left(\mathrm{PF}_{6}^{-}\right)\end{array}$ & $\begin{array}{c}\mathrm{E}_{\mathrm{pc}} \pm 0.002 \mathrm{~V}, \mathrm{ClO}_{4}^{-} \\
\left(\mathrm{PF}_{6}^{-}\right)\end{array}$ & $\begin{array}{l}\Delta E_{\mathrm{p}}, \mathrm{ClO}_{4}^{-} \\
\quad\left(\mathrm{PF}_{6}^{-}\right)\end{array}$ & $\begin{array}{l}\text { charge ratio, } Q_{\mathrm{a}} / Q_{\mathrm{c}}, \mathrm{ClO}_{4}^{-} \\
\qquad\left(\mathrm{PF}_{6}^{-}\right)\end{array}$ & $\begin{array}{l}\text { no. of } \mathrm{e}^{-}, n, \mathrm{ClO}_{4}^{-} \\
\qquad\left(\mathrm{PF}_{6}^{-}\right)\end{array}$ \\
\hline 10 & $-0.801(-0.837)$ & $-0.863(-0.903)$ & $0.062(0.066)$ & $0.87(0.87)$ & $1.04(1.10)$ \\
\hline 25 & $-0.780(-0.846)$ & $-0.847(-0.908)$ & $0.067(0.062)$ & $0.85(0.88)$ & $1.12(1.04)$ \\
\hline 75 & $-0.760(-0.836)$ & $-0.822(-0.901)$ & $0.062(0.065)$ & $0.88(0.89)$ & $1.04(1.09)$ \\
\hline 100 & $-0.745(-0.837)$ & $-0.807(-0.893)$ & $0.062(0.067)$ & $0.87(0.89)$ & $1.04(1.12)$ \\
\hline 20 & $-0.720(-0.826)$ & $-0.786(-0.883)$ & $0.066(0.067)$ & $0.87(0.88)$ & $1.10(1.12)$ \\
\hline
\end{tabular}

concentration at the electrode is so minuscule that little anodic current is produced. The Levich equation (eq 3) establishes relationship between current at the RDE and concentration of the analyte. In the Levich equation,

$$
i_{\text {lim }}=(0.620) n F A D^{2 / 3} \omega^{1 / 2} v^{-1 / 6} C
$$

$i_{\mathrm{lim}}$ is the limiting current density $\left(\mathrm{A} \mathrm{cm}^{-2}\right), n$ is the number of electrons involved in the reaction, $F$ is the Faraday constant (96 $500 \mathrm{C} \mathrm{mol}^{-1}$ ), $D$ is the diffusion coefficient of oxygen in the solution, $v$ is the kinematic viscosity of the solution $(4.4 \times$ $\left.10^{-3} \mathrm{~cm}^{2} \mathrm{~s}^{-1}\right), C$ is the concentration of oxygen in solution $(8.1$ $\mathrm{mM}),{ }^{8,9}$ and $\omega$ is the angular frequency $(2 \pi f / 60)$. The RDE data provide insight into the number of electrons transferred to the analyte by comparing the limiting currents to the rotation rate of the electrode. Figure 3B displays the Levich plot for the reduction of oxygen from the RDE data presented in Figure 3A. A linear Levich plot passing through the origin indicates

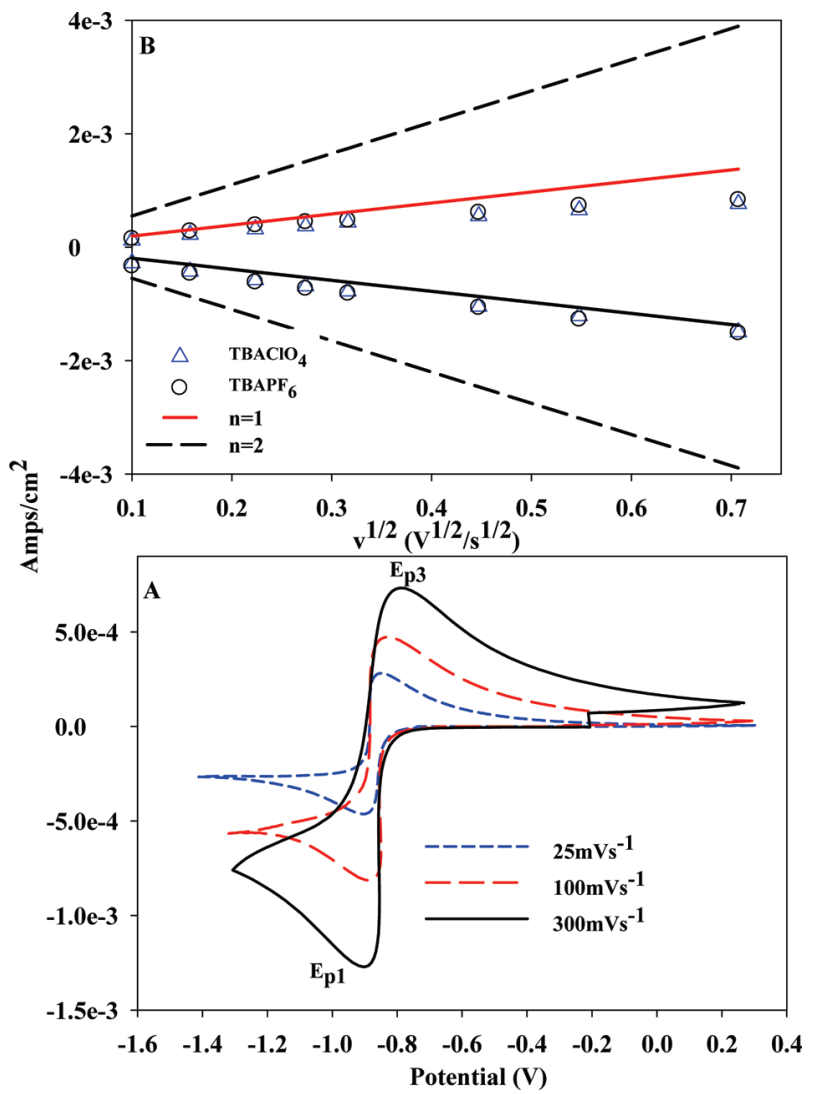

Figure 2. (A) Cyclic voltammograms for the reduction of oxygensaturated $0.1 \mathrm{M} \mathrm{TBAPF} / \mathrm{MeCN}$ on GC electrode at sweep rates $0.3 \mathrm{~V}$ $\mathrm{s}^{-1}$ (solid), $0.1 \mathrm{~V} \mathrm{~s}^{-1}$ (long dash), and $0.025 \mathrm{~V} \mathrm{~s}^{-1}$ (short dash). (B) Randles-Sevcik plot of peak current versus square root of the scan rate for the curves in $0.1 \mathrm{M} \mathrm{TBAPF}_{6}$ and $0.1 \mathrm{M} \mathrm{TBAClO}_{4} / \mathrm{MeCN}$. that mass transfer of oxygen from the bulk solution to the electrode surface controls the limiting current. The experimental Levich parallels the theoretical line when $n=1$, where $n$ is the number of electrons, indicating that the reduction of oxygen at this electrode is a one-electron process to form superoxide. These CVs and the RDE data are consistent with the reaction scheme 1 for the reduction of $\mathrm{O}_{2}$ in acetonitrile.

Scheme 1:

step 1. $\mathrm{O}_{2}+\mathrm{TBA}^{+}+\mathrm{e}^{-}=\mathrm{TBAO}_{2}$

step 2. $\mathrm{TBAO}_{2}+\mathrm{TBA}^{+}+\mathrm{e}^{-}=\mathrm{TBA}_{2} \mathrm{O}_{2}$

The peak $E_{\mathrm{p} 1}$ in the $\mathrm{CV}$ corresponds to step 1 and $E_{\mathrm{p} 2}$ to step 2 . We calculated the diffusion coefficient of $\mathrm{O}_{2}$ from the dependency of $\mathrm{I}_{\mathrm{pc}}$ on $V^{1 / 2}$ (from the Randles-Sevcik equation). The diffusion coefficient for $\mathrm{O}_{2}\left(D_{\mathrm{O}_{2}}\right)$ is found to be $2.2 \times 10^{-5} \mathrm{~cm}^{2}$ $\mathrm{s}^{-1}$ in $0.1 \mathrm{M} \mathrm{TBAClO} 4$ and $2.1 \times 10^{-5} \mathrm{~cm}^{2} \mathrm{~s}^{-1}$ in $0.1 \mathrm{M}$ $\mathrm{TBAPF}_{6}$. These values are very close to the previously reported values of $4.87 \times 10^{-5} \mathrm{~cm}^{2} \mathrm{~s}^{-1}$ in $0.9 \mathrm{M} \mathrm{TEABF}_{4}$ and $2.07 \times$ $10^{-5} \mathrm{~cm}^{2} \mathrm{~s}^{-1}$ in acetonitrile containing $0.1 \mathrm{M}$ TEAP. ${ }^{10,11} \mathrm{We}$

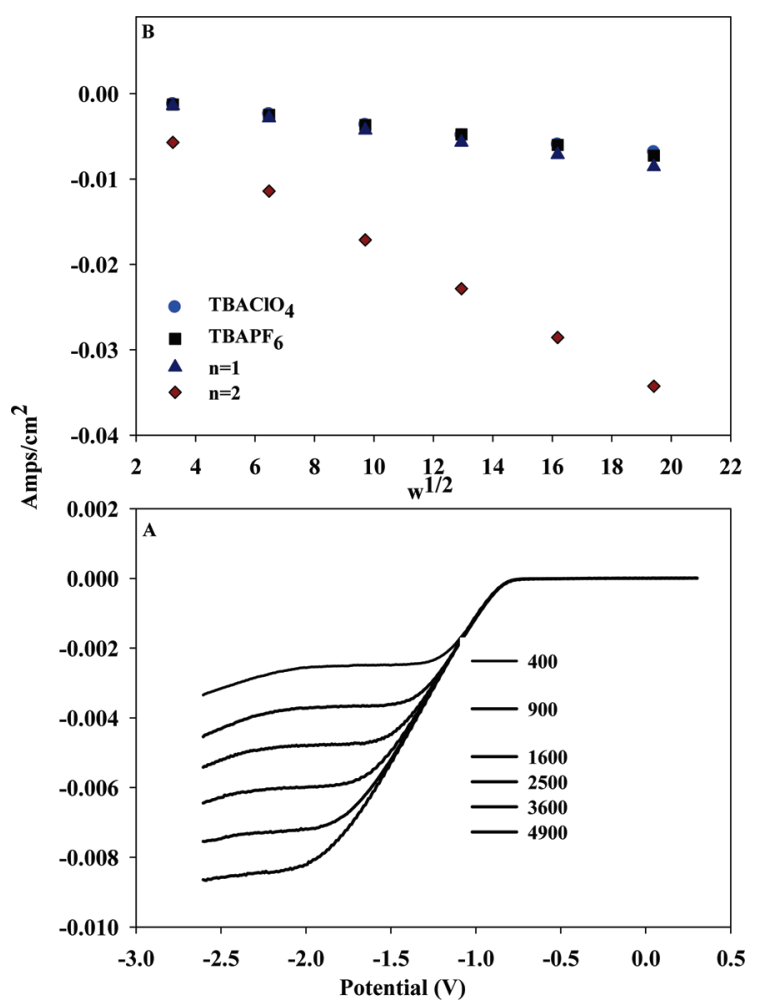

Figure 3. (A) Disk currents obtained in $0.1 \mathrm{M} \mathrm{TBAPF}_{6} \mathrm{MeCN}$ during ORR in the anodic sweep at room temperature by various rotation rates at $100 \mathrm{mV} \mathrm{s}^{-1}$. (B) Levich plot of limiting current versus square root of rotation in $0.1 \mathrm{M} \mathrm{TBAPF}_{6}$ and $0.1 \mathrm{M} \mathrm{TBAClO}_{4}$ in $\mathrm{MeCN}_{\text {versus }}$ $\mathrm{Ag} / \mathrm{AgCl}$ at scan rate $=100 \mathrm{mV} \mathrm{s}^{-1}$. 


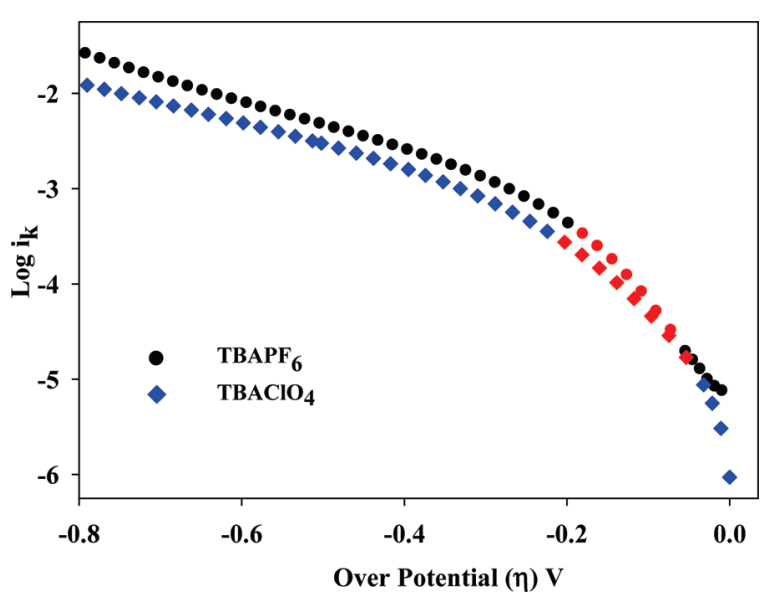

Figure 4. Tafel plots for ORR at room temperature on a glassy carbon electrode at $2500 \mathrm{rpm}$ for cathodic sweep 0 to $-1.0 \mathrm{~V}$. (OCP: $\mathrm{TBAPF}_{6}$ $-0.25 \mathrm{~V}$ and $\mathrm{TBAClO}_{4}-0.34$ versus $\mathrm{Ag} / \mathrm{AgCl}$ ). The Tafel region is indicated in red.

also calculated the diffusion coefficients of oxygen using the Levich method for $\mathrm{ClO}_{4}^{-}\left(2.3 \times 10^{-5} \mathrm{~cm}^{2} \mathrm{~s}^{-1}\right)$ and $\mathrm{PF}_{6}^{-}(2.1$ $\left.\times 10^{-5} \mathrm{~cm}^{2} \mathrm{~s}^{-1}\right)$. Again, the small difference in the diffusion coefficient values between both the Randles-Sevcik and the Levich equations may be ascribed to the fact that the Randles-Sevcik equation does not contain the term for mass transport control. Deviation from linearity at the lower rotation rates in Figure 3A is attributed to poor mass transport or slow kinetics. The data presented above indicate that the most likely pathway for oxygen reduction is by an initial one-electron transfer to $\mathrm{O}_{2}$ to form $\mathrm{O}_{2}{ }^{-}$. We can utilize the Stokes-Einstein equation to calculate the theoretical diffusion coefficient for $\mathrm{O}_{2}$ in this electrolyte and account for the small differences in the diffusion coefficients. The relationship between diffusion coefficient and solution viscosity is given by the Stokes-Einstein (eq 4).

$$
D=\frac{k T}{6 \pi \mu a}
$$

where $a$ is the effective hydrodynamic radius of oxygen, $k$ is the Boltzmann constant, $T$ is the temperature, and $\mu$ is the dynamic viscosity. The latter was calculated from the aforementioned kinematic viscosity, and the solution density and was found to be $0.384 \mathrm{cP}$. Using the Stokes-Einstein relationship we calculated $D_{\mathrm{O}_{2}}=2.6 \times 10^{-5} \mathrm{~cm}^{2} \mathrm{~s}^{-1}$. The $\mathrm{O}_{2}$ hydrodynamic radius used for this calculation was $2.16 \AA^{12}$. The Randles-Sevcik equation can also be applied to obtain the diffusion coefficient of the superoxide $\left(D_{\mathrm{O}_{2}}{ }^{-}\right)$generated; values obtained were $8.4 \times$ $10^{-6} \mathrm{~cm}^{2} \mathrm{~s}^{-1}$ in $0.1 \mathrm{M} \mathrm{TBAClO}_{4}$ and $9 . \times 10^{-6} \mathrm{~cm}^{2} \mathrm{~s}^{-1}$ for 0.1 $\mathrm{M} \mathrm{TBAPF}_{6}$, approximately 1 order of magnitude lower than that of $\mathrm{O}_{2}$. The diffusion coefficients of $\mathrm{O}_{2}$ and $\mathrm{O}_{2}{ }^{-}$are of particular interest to understand and model mass transport of these species in the Li-air battery. We investigated the nature of the reduction further using the Tafel equation, which relates the rate of electrochemical reaction to overpotential according to

$$
\log i=\log i_{0}+\left(\frac{1-\alpha n F}{R T}\right) \eta
$$

A plot of $\log i$ versus overpotential $(\eta)$ should be linear, from which the transfer coefficient $\alpha$ and the exchange current density
TABLE 4: $\mathrm{O}_{2} / \mathrm{O}_{2}^{-}$Kinetic Parameters in 0.1 $\mathrm{M} \mathrm{TBAPF}_{6}$ and $\mathrm{TBAClO}_{4} / \mathrm{MeCN}$

\begin{tabular}{cll}
\hline \multicolumn{1}{c}{ anions } & $(\eta): \mathrm{ClO}_{4}^{-}$ & $(\eta): \mathrm{PF}_{6}^{-}$ \\
\hline $\begin{array}{l}\text { Tafel slope }(\mathrm{mV} \mathrm{dec} \\
\text { exchange current } \\
\text { density }\left(i_{0}\right)\left(\mathrm{A} \mathrm{cm}^{-2}\right)\end{array}$ & 115 & 111 \\
$\begin{array}{r}\text { rate constant }\left(k^{\circ}\right) \\
\left(\mathrm{cm} \mathrm{s}^{-1}\right)\end{array}$ & $2.33 \times 10^{-5}$ & $4.44 \times 10^{-5}$ \\
$\alpha$ & $0.45 \times 10^{-4}$ & $2.89 \times 10^{-4}$ \\
\end{tabular}

$i_{0}$ can be determined. Figure 4 shows cathodic Tafel plots obtained after the measured current is corrected for mass transport to give the kinetic current. The kinetic current is calculated from the equation

$$
i_{\mathrm{k}}=\frac{i_{\mathrm{lim}} i}{i_{\lim }-i}
$$

where $i_{\mathrm{k}}$ is the kinetic current density, $i$ is the measured current density during $\mathrm{O}_{2}$ reduction, and $i_{\text {lim }}$ is the diffusion limited current density. The Tafel slope is consistent with a reversible one-electron reduction to superoxide (step 1), as the slope is very close to $120 \mathrm{mV} \mathrm{dec}{ }^{-1}$. This indicates that step 1 is rate determining. The reversibility of this step is evident from the kinetic data listed in Table 4 . The exchange current, $\log i_{0}$, is defined as the intersection of the Tafel line and the $y$-axis $\left(\log I_{\mathrm{k}}\right)$. The standard rate constant $k^{\mathrm{o}}$ is calculated from $i_{0}$ using eq 7.

$$
i_{0}=n F A k^{\circ} C
$$

We established that the anion has very little effect on the mechanism of reduction in this media. Both perchlorate and hexafluorophosphate solutions exhibit very similar electrochemical behavior.

3.2. Oxygen Reduction in Alkali Metal-Hexafluorophosphate $\left(\mathbf{A}^{+} \mathbf{P F}{ }^{-}{ }_{6}\right)$-Based Electrolytes. The electrochemical behavior of oxygen in the presence of alkali metal cations differed from that observed in the TBA-based electrolytes. Figure 5A illustrates the considerable difference in electrochemistry when the TBA cation is substituted with alkali metal cations such as lithium (Li), sodium (Na), and potassium (K). Reversibility or lack thereof is a major difference between the TBA-based electrolytes and the alkali solutions. Reversible systems correspond to a half-wave potential $E_{1 / 2}$ that is near the peak potential $E_{\mathrm{p}}$. Figure $5 \mathrm{~A}$ illustrates the irreversible nature of these systems. The reduction wave is broadened by the sluggish kinetics, leading to a displacement in potential between $E_{1 / 2}$ and $E_{\mathrm{p}}$. The relevant voltammetric properties are listed in Table 5. Although the CVs appear relatively mundane, these systems are a lot more complex upon closer inspection. The cathodic peak is shifted from $-0.84 \mathrm{~V}$ as in the case of the TBA cation to ca. $-0.7 \mathrm{~V}$ at the scan rate of $25 \mathrm{mV} \mathrm{s}^{-1}$. The peak shifts are possibly the result of the relative Lewis acidities of the cations. Both sodium and lithium cations are recognized as hard Lewis acids due to their small ionic radii $\mathrm{Li}^{+}(0.90 \AA)$ and $\mathrm{Na}^{+}(1.16 \AA)$ and low oxidation states. Hard Lewis acids have high charge densities on their surface and tend to form ionic bonds with hard bases such as superoxide. The appearance of a second cathodic peak, which is characterized by the plateau region at $-1.5 \mathrm{~V}$, was a distinct feature of the $\mathrm{LiPF}_{6}$ case. Investigation of the plateau region was conducted by varying the scan rate (Figure $5 \mathrm{~B}) . E_{\mathrm{p} 2}$ is associated with the 


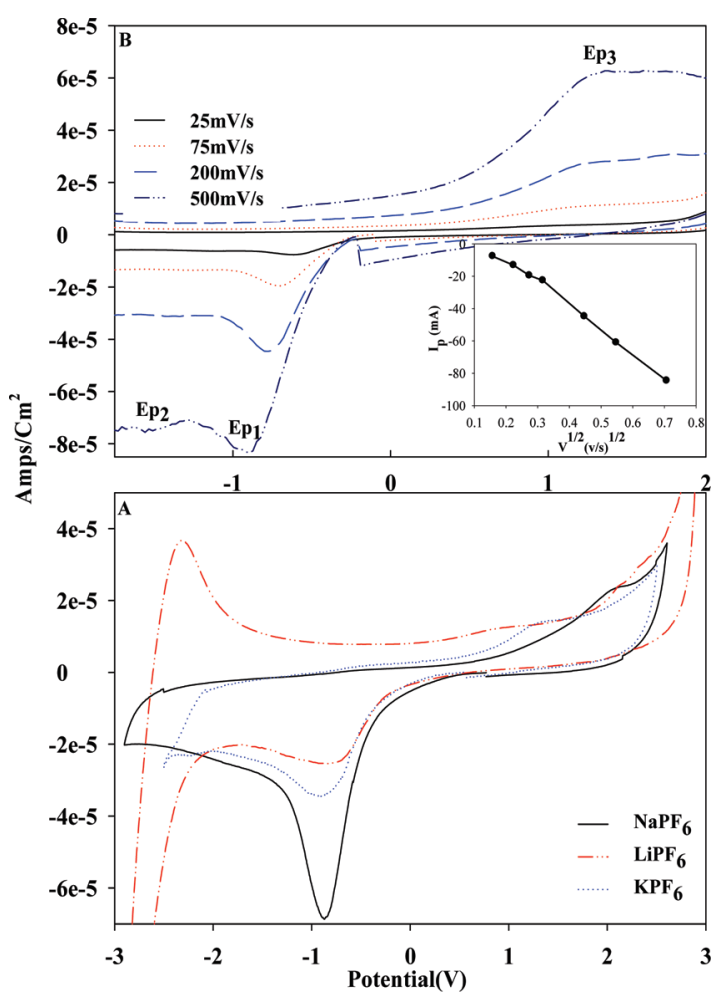

Figure 5. (A) Cyclic voltammograms of oxygen reduction in $0.1 \mathrm{M}$ $\mathrm{LiPF}_{6}$ (dashed line), $0.1 \mathrm{M} \mathrm{NaPF}_{6}$ (solid line), and $\mathrm{KPF}_{6}$ (dash-dotted line) in $\mathrm{MeCN}$. Scan rate $=100 \mathrm{mV} \mathrm{s}^{-1}$ ( -3 to $3 \mathrm{~V}$ versus $\mathrm{Ag} / \mathrm{AgCl}$ ). (B) Oxygen reduction voltammograms in $0.1 \mathrm{M} \mathrm{LiPF}_{6} / \mathrm{MeCN}$ on GC electrode at various sweep rates. (Inset) Nicholson \& Shain plot.

TABLE 5: Voltammetric Properties of $0.1 \mathrm{M} \mathrm{Li}, \mathrm{Na}$, and $\mathrm{KPF}_{6}$ in Oxygen Saturated Acetonitrile ${ }^{a}$

\begin{tabular}{lllllllll}
\hline & & & & & & $\begin{array}{c}k^{\circ} \\
\left(\mathrm{cm} \mathrm{s}^{-1}\right)\end{array}$ & $\begin{array}{c}\text { diffusion } \\
\text { coefficient } \\
\left(\mathrm{cm}^{2} \mathrm{~s}^{-1}\right)\end{array}$ \\
\hline $\mathrm{Li}^{+}$ & -0.71 & -1.30 & 1.8 & -0.580 & 0.225 & $8.10 \times 10^{-5}$ & $3.77 \times 10^{-7}$ \\
$\mathrm{Na}^{+}$ & -0.76 & & & -0.730 & 0.190 & $6.97 \times 10^{-4}$ & $1.03 \times 10^{-6}$ \\
$\mathrm{~K}^{+}$ & -0.78 & & 1.2 & -0.677 & 0.230 & $1.97 \times 10^{-4}$ & $2.30 \times 10^{-7}$
\end{tabular}

${ }^{a}$ Scan rate $=25 \mathrm{mV} \mathrm{s}^{-1}$.

successive reduction of lithium superoxide to lithium peroxide through the "chemical" reaction in step 2 and "electrochemical" reaction in step 3. Note that the appearance of the peak $E_{\mathrm{p} 2}$ corresponding to lithium superoxide reduction is scan rate dependent. The lack of this feature at low scan rates reveals that the kinetics of this process is extremely rapid. On the reverse sweep to positive potentials, this peroxide reduction product is oxidized at high overpotentials via the reaction in step $4\left(E_{\mathrm{p} 3}\right.$ $=1.3 \mathrm{~V}$ ). This peak is analogous to peroxide oxidation observed in TBA salt solutions. This oxidation peak is absent in the sodium CV probably as a result of the decomposition of sodium superoxide to sodium peroxide via reaction in step 2 (scheme 3). Lithium peroxide decomposes slightly in a similar manner to sodium peroxide but not to the same extent. This explains the absence of the peak corresponding to the reduction of $\mathrm{LiO}_{2}$ at slow scan rates. The electrochemical reduction of oxygen in these solutions is irreversible. The cathodic peak current is directly proportional to the square root of scan rate (inset of Figure 5B), indicating a fast diffusion controlled reaction. The initial electrode processes can be described by similar reactions for $\mathrm{O}_{2}$ reduction in presence of both $\mathrm{Li}^{+}$and $\mathrm{Na}^{+}$as depicted in schemes 2 and 3, respectively.
Scheme 2:

step $1\left(E_{\mathrm{p} 1}\right) \cdot \mathrm{O}_{2}+\mathrm{Li}^{+}+\mathrm{e}^{-}=\mathrm{LiO}_{2}$,

$$
E^{\circ}=3.0 \mathrm{~V}\left(\mathrm{Li} / \mathrm{Li}^{+}\right) \text {or }-0.2 \mathrm{~V}(\mathrm{Ag} / \mathrm{AgCl})
$$

step 2. $2 \mathrm{LiO}_{2}=\mathrm{Li}_{2} \mathrm{O}_{2}+\mathrm{O}_{2}$

step $3\left(E_{\mathrm{p} 2}\right) . \mathrm{LiO}_{2}+\mathrm{Li}^{+}+\mathrm{e}^{-}=\mathrm{L}_{2} \mathrm{O}_{2}, E^{\circ}=3.1 \mathrm{~V}$

step $4\left(E_{\mathrm{p} 3}\right) \cdot \mathrm{Li}_{2} \mathrm{O}_{2}=\mathrm{O}_{2}+2 \mathrm{Li}^{+}+2 \mathrm{e}^{-}$

Scheme 3:

step $1\left(E_{\mathrm{p} 1}\right) \cdot \mathrm{O}_{2}+\mathrm{Na}^{+}+\mathrm{e}^{-}=\mathrm{NaO}_{2}$

step 2. $2 \mathrm{NaO}_{2}=\mathrm{Na}_{2} \mathrm{O}_{2}+\mathrm{O}_{2}$

Oxygen is reduced to lithium superoxide via reaction step $1\left(E_{\mathrm{p} 1}\right)$. Knowing the thermodynamic quantity $\Delta G$, (Gibbs free energy) the lithium cell potential may be obtained from the equation

$$
-\Delta G=n F E^{\circ}
$$

The calculated $E^{\circ}$ valueis presented in scheme 2 for the lithium case.

According to eq $9,{ }^{13}$ the transfer coefficient maybe approximated from the difference between the peak potential and the half-wave peak potential (see Table 5). The low $\alpha n$ values, which are not in the typical region of 0.5 , suggest sluggish kinetics due to the formation of a passive oxide layer on the surface of the electrode.

$$
E_{\mathrm{p}}-E_{\mathrm{p} / 2}=\frac{1.857 R T}{\alpha n}=\frac{47.7}{\alpha} \mathrm{mV}
$$

The rate constant may also be calculated if the diffusion coefficient is known. According to Nicholson and co-worker, ${ }^{14,15}$ an irreversible cathodic reaction modeled through the relationship between $I_{\mathrm{p}}$ and $V^{1 / 2}$ is linear and is described by eq 10 .

$$
I_{\mathrm{p}}=\left(2.99 \times 10^{5}\right) n(n \alpha)^{1 / 2} A C D^{1 / 2} V^{1 / 2}
$$

The diffusion coefficient of oxygen in these alkali-metal-based salts can be estimated using this equation along with the calculated $\alpha$ values. In eq $10, I_{\mathrm{p}}$ is the peak current, $A$ is the area of the electrode, $C$ is the concentration of oxygen, and $V$ is the scan rate. A plot of $V^{1 / 2}$ versus $I_{\mathrm{p}}$ shown in Figure 6 contains both the experimental plots using data collected and the simulated plots for $n=1$. From these plots, the number of electrons involved in the first reduction process is determined to be one. This confirms that the overall reduction of oxygen in these salts is a one-electron process to form an alkali metal superoxide. The diffusion coefficients of the alkali salts are presented in Table 5. These are 1 order of magnitude lower than their TBA counterparts. The standard rate constants of these reactions are calculated from plotting $\ln \mathrm{I}_{\mathrm{p}}$ vs overpotential. The $k^{\circ}$ values show that $\mathrm{O}_{2}$ reduction kinetics in sodium salt solutions are compared to lithium- and potassium-based electrolytes. The irreversibility of these systems obvious from the lack of oxidation peaks in the sodium data even at high scans rates points to the chemical decomposition of the first reduction product. In order to understand the system in further detail, we examined oxygen reduction as a function of concentration. Figure 7 shows voltammograms for $1 \mathrm{M} \mathrm{APF}_{6}\left(\mathrm{~A}=\mathrm{Li}^{+}, \mathrm{Na}^{+}\right.$, and $0.5 \mathrm{M} \mathrm{K}^{+}$) in $\mathrm{MeCN}$, scanned at $100 \mathrm{mV} \mathrm{s}^{-1}$. For the cases 


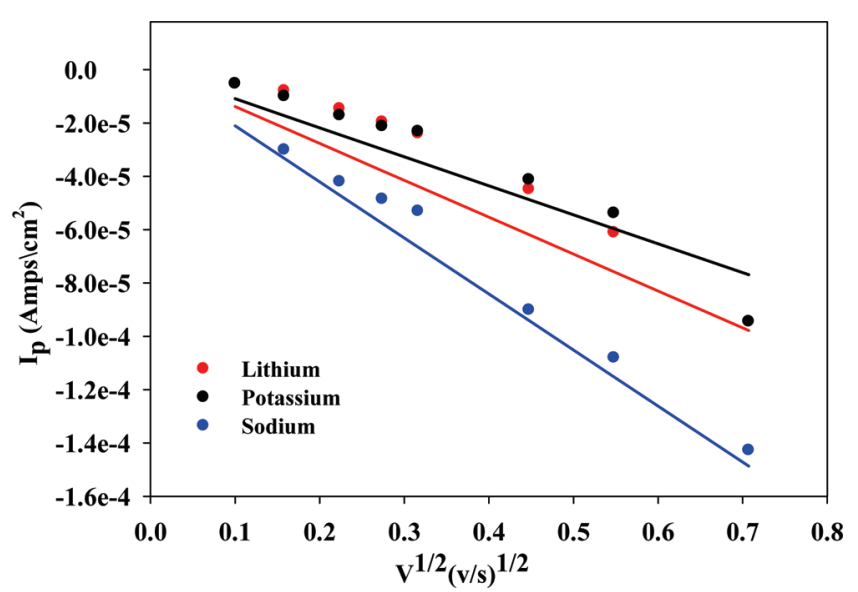

Figure 6. Experimental and theoretical $(n=1) \sqrt{ } \mathrm{v}$ versus $I_{\mathrm{p}}$ plots for in $0.1 \mathrm{M} \mathrm{LiPF}_{6}, \mathrm{NaPF}_{6}$, and $\mathrm{KPF}_{6}$ in $\mathrm{MeCN}$.

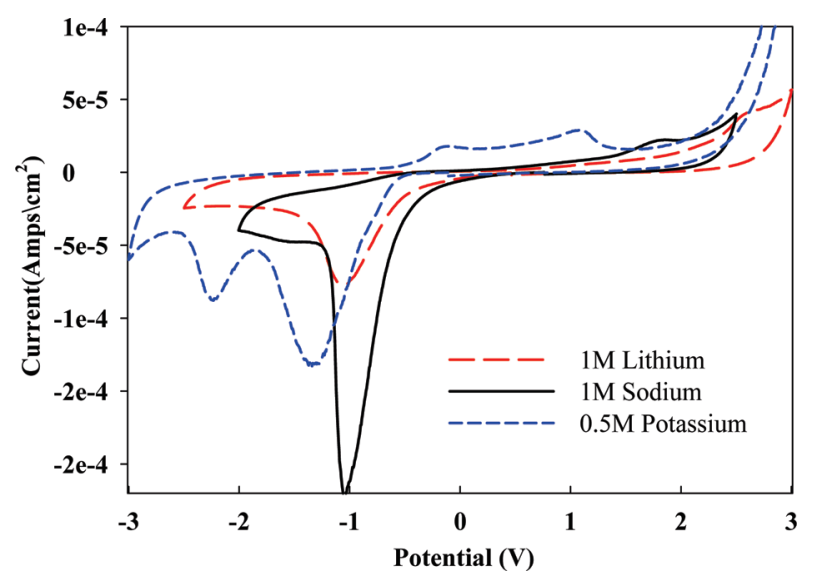

Figure 7. Cyclic voltammograms for the reduction of oxygen-saturated $1 \mathrm{M} \mathrm{XPF}_{6}\left(\mathrm{X}=\mathrm{Li}^{+}, \mathrm{Na}^{+}\right.$, and $\left.0.5 \mathrm{M} \mathrm{K}^{+}\right)$in $\mathrm{MeCN}$ on $\mathrm{GC}$ electrode at $100 \mathrm{mV} \mathrm{s}^{-1}$.

of sodium and lithium, results are similar to those in $0.1 \mathrm{M}$ solutions although there was a shift in the anodic peak position in the lithium case. Increasing the concentration of alkali salts facilitates oxidation of the reduction products. Increased concentrations of cations stabilize the superoxide and peroxide products. The electrochemistry of oxygen is influenced by the cation size; increasing the cation size from lithium to potassium alters the cyclic voltammogram. Potassium is a larger alkali metal ( $r=2.20 \AA$ ). The $\mathrm{CV}$ for $0.1 \mathrm{M} \mathrm{KPF}_{6}$ is comparable to those for $\mathrm{Li}$ and $\mathrm{Na}$ salt solutions. At high concentrations, it is reminiscent of the TBA electrolytes; notice two reduction peaks followed by two subsequent oxidation peaks observed on the return sweep in the range. Applying RDE voltammetry to these systems was unsuccessful. This is illustrated in Figure 8 where it is interesting to note that there is little increase in current density as the electrode is rotated; in fact, the current decreases. It appears that the reduction product passivates the electrode, and as the rotation rate increases so does the passivation rate. The electrode appears to passivate quicker than mass transport limit can be reached. The same behavior is observed for $\mathrm{NaPF}_{6}$, although it occurs much faster. Thus, the RDE data provide additional support to the notion that the reduction products of oxygen passivate the electrode. Figure 9 shows the typical steady-state voltammograms obtained on the $\mathrm{RDE}$ in $\mathrm{O}_{2-}$ saturated solution containing 0.1 and $1 \mathrm{M} \mathrm{KPF}_{6}$. These voltammograms do not show a clear limiting current due to mass transport limitations. However, the formation of a slight horizontal current plateau during oxygen reduction is observed.

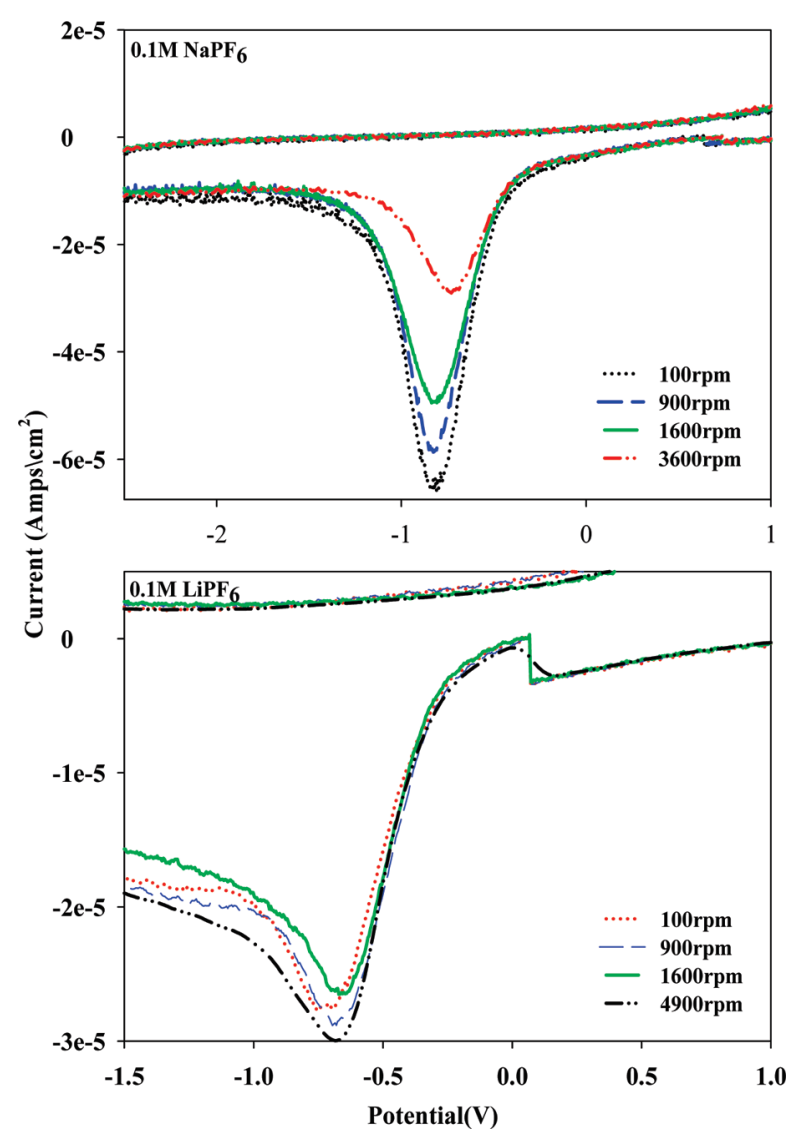

Figure 8. Steady voltammograms for the reduction of oxygen in $0.1 \mathrm{M} \mathrm{LiPF}_{6}$ and $\mathrm{NaPF}_{6}$ in $\mathrm{MeCN}$ at various rotation rates at 100 $\mathrm{mV} \mathrm{s}^{-1}$.

The formation of this plateau at potentials less negative than $-1 \mathrm{~V}$ is indicative of a competitive secondary reduction at the electrode. This may be the reason behind the overlapping oxygen reduction peaks, especially in the $1 \mathrm{M}$ solution.

In summary, the data we obtained in $\mathrm{TBAClO}_{4}$ - and $\mathrm{TBAPF}_{6^{-}}$ based electrolytes reveal that the anion has little or no effect on the redox processes. In TBA salt solutions, the first reduction process is a one-electron reversible reduction of oxygen to form the superoxide. The superoxide can be reduced to the peroxide irreversibly at lower potentials. Alkali metal hexafluorophosphate $\mathrm{APF}_{6}$ (where $\mathrm{A}$ is $\mathrm{Li}^{+}, \mathrm{Na}^{+}$, and $\mathrm{K}^{+}$) solutions were investigated to establish the effect of cations on oxygen electrochemistry. By replacing the larger $\mathrm{TBA}^{+}$with alkali metal cations, the reversible nature of oxygen reduction is severely suppressed. The reduction reaction in solutions containing the smaller cations $\mathrm{Li}^{+}$and $\mathrm{Na}^{+}$is irreversible. In $\mathrm{LiPF}_{6}$ solutions, $\mathrm{O}_{2}$ is irreversibly reduced first by a one-electron process to form $\mathrm{LiO}_{2}$, followed by a second one-electron reduction to $\mathrm{Li}_{2} \mathrm{O}_{2}$ which appears to passivate the electrode surface, making the reaction irreversible. It also appeared that the $\mathrm{LiO}_{2}$ formed on the electrode surface chemically decomposes to $\mathrm{Li}_{2} \mathrm{O}_{2}$. However, there is a finite lifetime for the $\mathrm{LiO}_{2}$ on the electrode surface with the result that at high scan rates the reduction of $\mathrm{LiO}_{2}$ to $\mathrm{Li}_{2} \mathrm{O}_{2}$ can be observed. Both $\mathrm{LiO}_{2}$ and $\mathrm{Li}_{2} \mathrm{O}_{2}$ can be oxidized at high overvoltages to oxygen and lithium. Oxygen reduction in $\mathrm{NaPF}_{6}$ is also a one-electron process, first forming $\mathrm{NaO}_{2}$, which appears to passivate the surface, as well as decomposing rapidly to $\mathrm{Na}_{2} \mathrm{O}_{2}$, hence the complete lack of oxidation. The sodium oxides cannot be oxidized even at high overvoltages, except in highly concentrated electrolyte solutions. Potassium is a slightly larger alkali metal (radius $=2.2 \AA$ ) and displays a 


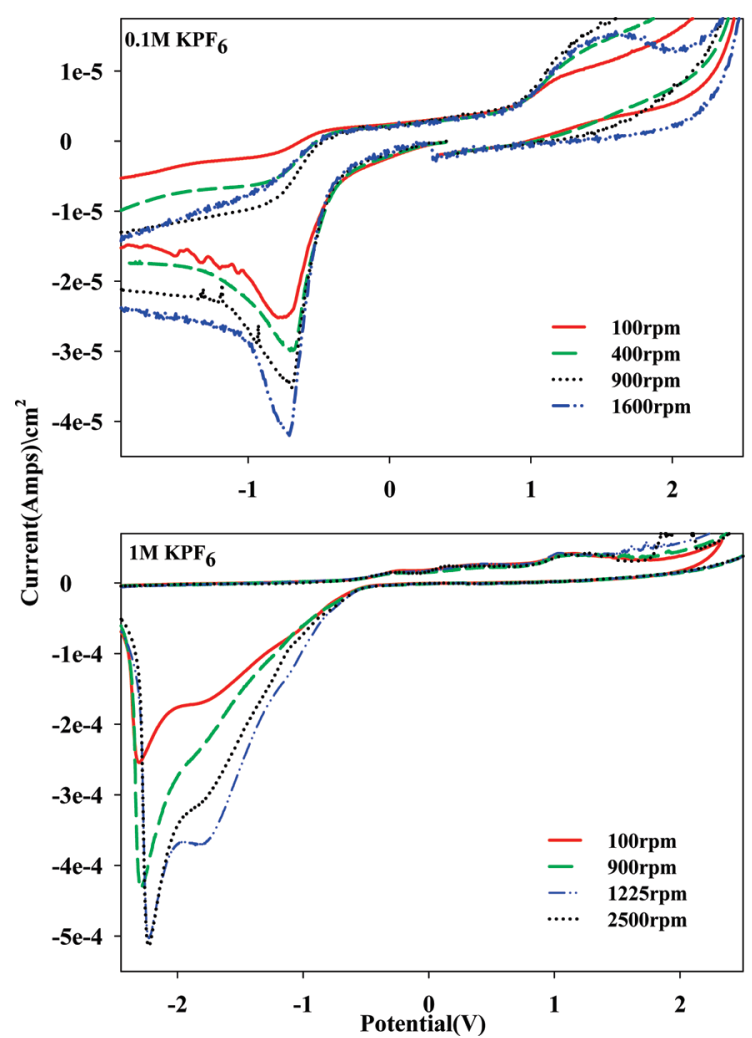

Figure 9. Disk currents obtained in 0.1 and $1 \mathrm{M} \mathrm{KPF}_{6} \mathrm{MeCN}$ during ORR in the anodic sweep at room temperature at various rotation rates. All scans used a glassy carbon working electrode at a scan rate of 100 $\mathrm{mV} \mathrm{s}^{-1}$.

voltammogram that is somewhat quasi-reversible as verified by the increase of anodic current in comparison to lithium and sodium. Although the oxygen reduction is not as reversible as that in the tetraalkylammonium salt solutions, the reduction of $\mathrm{O}_{2}$ to $\mathrm{KO}_{2}$ and $\mathrm{KO}_{2}$ to $\mathrm{K}_{2} \mathrm{O}_{2}$ is observed as two distinct peak as opposed to the mix potential regions of lithium and sodium at $1 \mathrm{M}$ concentration. Both of these oxides are electrochemically oxidized at significant overpotentials. These results maybe explained in terms of the charge density on the surfaces of the cations. The smallest of the cations $\mathrm{Li}^{+}$is a good Lewis acid capable of forming a very strong ionic bond with the superoxide ion. Increasing the cation size from $\mathrm{Li}^{+}$to $\mathrm{TBA}^{+}\left(\mathrm{TBA}^{+}<\mathrm{K}^{+}\right.$ $<\mathrm{Na}^{+}<\mathrm{Li}^{+}$), the positive charge density (charge per unit volume) on the ion decreases, as does the relative Lewis acidity, leading to weaker interactions with the superoxide ion. This has several consequences: The $\mathrm{TBAO}_{2}$ is soluble in the electrolyte, and the redox reaction is reversible. The $\mathrm{KO}_{2}$ formed appears to have partial solubility in the electrolyte with the result that the redox processes are somewhat reminiscent of those in the TBA solutions. The smaller $\mathrm{Li}$ and $\mathrm{Na}$ cations are stronger Lewis acids, and they form ionic bonds with oxides leading to their precipitation on the electrode surfaces. This surface coverage of the electrode by the $\mathrm{O}_{2}$ reduction products passivates the electrode, shuts down the reduction, and renders the reaction irreversible.

\section{Conclusions}

Our results show that the reduction and subsequent oxidation of $\mathrm{O}_{2}$ in acetonitrile-based electrolytes is strongly influenced by the cation of the conducting salt used. A practical outcome of the results from this work to the lithium-air battery is that it would be advantageous to use a mixture of $\mathrm{Li}$ and $\mathrm{K}$ and/or TBA salts as supporting electrolytes in order to dissolve the oxygen reduction products. This in turn would increase the amount of oxygen that can be reduced to deliver higher capacity. Dissolving the reduction products would also promote reversibility of $\mathrm{O}_{2}$ reduction, which would increase the battery's rechargeability. Our results also show that useful electrochemical kinetic data for soluble redox species in highly concentrated electrolyte solutions relevant to $\mathrm{Li}$ batteries can be obtained using the complementary CV and RDE techniques. Such kinetic data are relevant to the studies of the Li-air battery as well as others containing soluble electrode materials, especially for battery simulation studies aimed at understanding the performance of practical batteries, and generally for the development of improved materials.

Acknowledgment. U.S. Army CERDEC through Subcontract No. GTS-S- 6-1-437 supported this work.

\section{References and Notes}

(1) Abraham, K. M.; Jiang, Z. J. Electrochem. Soc. 1996, 143, 1-5.

(2) Read, J. J. Electrochem. Soc. 2006, 153, A96-A100.

(3) Ogasawara, T.; Debart, A.; Holzapfel, M.; Novak, P.; Bruce, P. G. J. Am. Chem. Soc. 2006, 128, 1390-1393.

(4) Johnson, E. L.; Pool, K. H.; Hamm, R. E. Anal. Chem. 1966, 38, 183-185.

(5) Maricle, D. L.; Hodgson, W. G. Anal. Chem. 1965, 37, 1562-1565. 1067

(6) Peover, M. E.; White, B. S. Electrochim. Acta 1966, 11, 1061-

(7) Sawyer, D. T.; Roberts, J. L. J. Electroanal. Chem. 1966, 12, 90101.

(8) Achord, J. M.; Hussey, C. L. Anal. Chem. 1980, 52, 601-602.

(9) Sawyer, D. T.; Chiericato, G.; Angelis, C. T.; Nanni, E. J.; Tsuchiya, T. Anal. Chem. 1982, 54, 1720-1724.

(10) Kishioka, S.-y. Electroanalysis 2001, 13, 1161-1164.

(11) Tsushima, M.; Tokuda, K.; Ohsaka, T. Anal. Chem. 1994, 66, 45514556.

(12) Bader, R. F. W.; Henneker, W. H.; Cade, P. E. J. Chem. Phys. 1967, 46, 3341-3363.

(13) Bard, A. J.; Faulkner, L. R. Electrochemical Methods Fundamentals and Applications, 2nd ed.; John Wiley \& Sons: New York, 2001; Vol 2.

(14) Nicholson, R. S. Anal. Chem. 1965, 37, 1351-1355.

(15) Nicholson, R. S.; Shain, I. Anal. Chem. 1964, 36, 706-723.

JP908090S 